\title{
Normal Pressure Hydrocephalus in a Human Immunodeficiency Virus
} Type 2 Patient

\section{Paraskevas GP*, Bougea A and Kapaki E}

$1^{\text {st }}$ Department of Neurology, National and Kapodisrtian University of Athens, Eginition Hospital, Athens, Greece

\begin{abstract}
A patient infected by human immunodeficiency virus type 2, developed shunt-responsive, normal pressure hydrocephalus. No other secondary cause including opportunistic infections, subarachnoid hemorrhage or trauma was detected, emphasizing the possible relationship between normal pressure hydrocephalus and infection by human immunodeficiency virus type 2. To the best of our knowledge, no human immunodeficiency virus type 2 patient with normal pressure hydrocephalus has been reported in the literature. This report aims to extend the spectrum of human immunodeficiency virus type 2 associated neurological complications.
\end{abstract}

Keywords: Human immunodeficiency virus type 2 (HIV-2); Normal pressure hydrocephalus (NPH), Highly active antiretroviral therapy (HAART)

\section{Introduction}

Normal Pressure Hydrocephalus (NPH) is a not uncommon neurological disorder among elderly adults, characterized by the typical triad of gait disorder, cognitive impairment and urinary incontinence, in the presence of ventriculomegaly and normal (or not significantly increased) Cerebrospinal Fluid (CSF) pressure on random lumbar puncture [1]. It is usually idiopathic, but may also be secondary to various conditions including subarachnoid hemorrhage, cranial trauma, and meningitis. NPH is considered to be an at least partially reversible cause of cognitive or movement disorder, and correctly identified patients may benefit from a shunt surgery [2].

Infection by Human Immunodeficiency Virus type 2 (HIV-2), although spread worldwide due to high immigration, it remains less common, less well documented and more difficult to treat with traditional Highly Active Antiretroviral Therapy (HAART) medications than HIV-1 [3]. Limited data on HIV-2 neurological complications exist, including opportunistic infections (toxoplasmosis, cryptococcosis, progressive multifocal leukoencephalopathy) and HIV dementia [35]. To the best of our knowledge no case of NPH has been reported secondary to HIV-2 infection.

\section{Case Report}

A 59 year old HIV-2 positive heterosexual woman was referred to our clinic due to gait difficulty, cognitive complaints and urinary incontinence. No symptom or sign of transient intracranial hypertension (headache, vomiting) was reported.

She had been identified as seropositive for HIV-2 at age 53. At that time, she presented with diarrhea, weight loss and oropharyngeal candidiasis and her CD4 cell count was 152 cells $/ \mathrm{mm}^{3}$. Due to mild unsteadiness, brain MRI was performed showing ventricular enlargement and T2 white matter hyperintensities, and a lesion within the right frontal subcortical white matter (Figure 1A-1C). Gadoliniumenhanced T1W imaging did not reveal abnormal enhancement. Further investigations ruled out toxoplasmosis, cryptoccocosis, or tuberculosis. She was started on HAART (lamivudine/zidovudine $200 \mathrm{mg} /$ day and iopinavir/ritonavir $50 \mathrm{mg} /$ day) and her CD4 cell count was increased to 280 cells $/ \mathrm{mm}^{3}$. Until now she remains without constitutional symptoms or opportunistic infections.

However, at age 56 ( 3 years ago) her mild unsteadiness turned to gradual walking difficulty with progressively short-stepped gait. At age
58 , one year prior to her admission urinary incontinence and difficulty in recalling recent events were added.

On examination the patient was alert and oriented. Tendon reflexes were brisk, and plantar responses were flexor bilaterally. Muscle tone and sensory examination were normal. Papilledema was absent. She exhibited a short-stride gait with shuffling. On neuropsychological testing (Table 1) cognitive decline was evident and compatible with a fronto-subcortical profile, with preserved memory function; however, frontal dysfunction was noted. Hematological, biochemical parameters and chest radiography were normal. CD4 cell count was 360 cells $/ \mathrm{mm}^{3}$. Serial brain MRIs revealed ventricular enlargement in the absence of severe cortical atrophy, with an Evans index increasing from 0.33 (7 years ago) to 0.36 (currently) and a callosal angle of $94^{\circ} \mathrm{C}$ (Figure 1D1O). A lumbar tap with removal of $40 \mathrm{ml}$ of CSF was performed. The opening CSF pressure was $17 \mathrm{~cm} \mathrm{H}_{2} \mathrm{O}$. No white cell or red cells were present. Protein and glucose concentrations were $19 \mathrm{mg} / \mathrm{dl}$, and $65 \mathrm{mg} /$ dl respectively.

Syphilis serology in both blood and CSF was negative. Molecular analysis (PCR) for infectious etiologies in CSF showed an absence of cytomegalovirus, varicella-zoster, herpes simplex type 1 and type 2, Epstein-Barr, human herpes 6 and JC viruses, as well as cryptococcus and tuberculosis. Cognitive function and gait were reassessed 72 hours post lumbar puncture. Our patient showed subjective improvement in cognitive and gait functions. Improvement was noted in tests of frontal function and gait (Table 1).

The following criteria were used to identify possible benefit from shunt: number of steps taken in a $10 \mathrm{~m}$ walking test and time needed to walk $10 \mathrm{~m}$ should be reduced by at least $20 \%$, and/or neuropsychological tests should show an improvement of at least 10\% [1]. Based on these criteria she was referred to the department of Neurosurgery and ventriculoperitoneal shunt surgery was performed. Six months after surgery cognitive function and gait remain improved (Table 1).

*Corresponding author: George P Paraskevas, Department of Neurology, $1^{\text {s }}$ Department of Neurology National and Kapodisrtian University of Athens, Eginition Hospital, 72 Vass Sofias Ave, 11528, Athens, Greece, Tel. ++30 210 7289285; Fax ++30 210 7216474; E-mail: geoprskvs44@gmail.com

Received May 24, 2014; Accepted June 24, 2014; Published June 26, 2014

Citation: Paraskevas GP, Bougea A, Kapaki E (2014) Normal Pressure Hydrocephalus in a Human Immunodeficiency Virus Type 2 Patient. J Clin Case Rep 4: 376. doi:10.4172/2165-7920.1000376

Copyright: @ 2014 Paraskevas GP, et al. This is an open-access article distributed under the terms of the Creative Commons Attribution License, which permits unrestricted use, distribution, and reproduction in any medium, provided the original author and source are credited. 


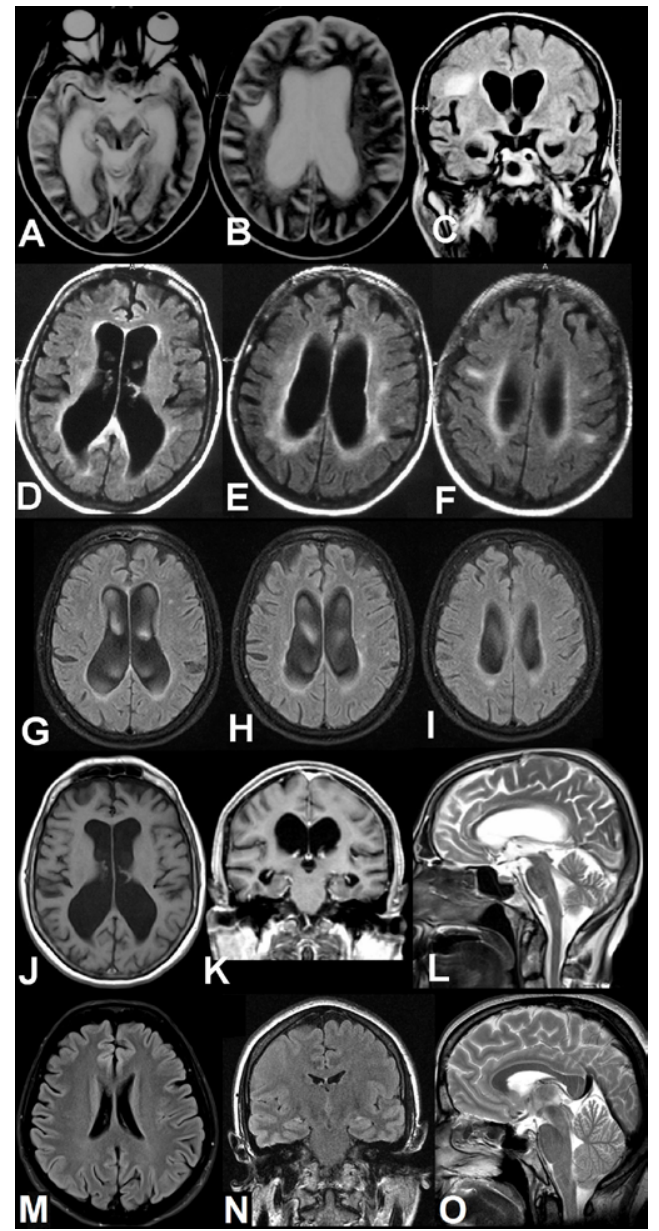

Figure 1: Magnetic resonance imaging of our patient At age of 53, T2weighted (Figure 1A-1B) and FLAIR (Figure 1C) images showing ventricular enlargement, white matter hyperintensities and ahyperintense lesion within the right frontal subcortical white matter. At age 54 (1 year later), FLAIR images (Figure $1 \mathrm{D}-1 \mathrm{~F})$ revealed the periventricular and subcortical white matter hyperintensities; however the larger frontal lesion has almost disappeared. At the time of admission (age 59,) FLAIR images (Figure 1G-1I) showed reduced white matter lesion load and ventriculomegaly. Ventricular enlargement is also seen in axial T1 (Figure 1J), coronal T1 (Figure 1K) and sagittal T2 (Figure 1L) images. For comparison, MRI images of a 58 years-old healthy female are shown: axial FLAIR (Figure 1M), coronal FLAIR (Figure $1 \mathrm{~N}$ ) and sagittal T2 (Figure 10).

\section{Discussion}

Our patient experienced the typical triad of symptoms of normal pressure hydrocephalus, with a chronic and insidious course. The etiology of her syndrome could be either idiopathic or secondary. Idiopathic NPH usually occurs in older age ( $>65-70$ years) [1], while our patient's age is more compatible with a secondary etiology. As regards secondary etiologies, no history of trauma, subarachnoid hemorrhage or meningitis (including opportunistic infections) was present in our patient. Thus, HIV-2 seems to be the only remaining possibility [6-9].

Hydrocephalus due to cerebral toxoplasmosis, cryptococcal and tuberculous meningitis in HIV patients is very rare and only few cases have been reported in the literature only for HIV-1 [10,11]. The mechanism of hydrocephalus in CNS toxoplasmosis may be due to compression of CSF pathways by ring enhancing lesions, but even in their absence, hydrocephalus may be due to ventriculitis [12]

\begin{tabular}{|l|l|l|l|l|l|} 
& Cut- off & $\begin{array}{l}\text { Before } \\
\text { lumbar } \\
\text { tap }\end{array}$ & $\begin{array}{l}\mathbf{7 2} \text { hours } \\
\text { after lumbar } \\
\text { tap }\end{array}$ & $\begin{array}{l}\text { Improvement } \\
\text { (\%) }\end{array}$ & $\begin{array}{l}\mathbf{6} \text { months } \\
\text { after shunt } \\
\text { surgery }\end{array}$ \\
\hline MMSE: & 27 & $24 / 30$ & $24 / 30$ & & 25 \\
\hline CLOX 1: & 11 & $8 / 15$ & $12 / 15$ & $50 \%$ & $12 / 15$ \\
\hline CLOX 2: & 12 & $11 / 15$ & $12 / 15$ & $9 \%$ & $12 / 15$ \\
\hline FAB & 15 & $13 / 18$ & $15 / 18$ & $15.4 \%$ & $15 / 18$ \\
\hline $\begin{array}{l}\mathbf{5} \text { words } \\
\text { immediate }\end{array}$ & & $5 / 5$ & $5 / 5$ & & $5 / 5$ \\
\hline $\mathbf{5}$ words delayed & & $4+1 / 5$ & $5 / 5$ & & $5 / 5$ \\
\hline $\begin{array}{l}\text { 10 m walking, } \\
\text { time (sec) }\end{array}$ & 10 & 14 & 12 & $14 \%$ & 12 \\
\hline $\begin{array}{l}\text { 10m walking, } \\
\text { steps }\end{array}$ & 13 & 26 & 20 & $23 \%$ & 19 \\
\hline
\end{tabular}

MMSE: Mini Mental State Examination [6].

CLOX 1 and CLOX 2: On demand and copying subtests (respectively) of the CLOX clock-drawing test [7].

FAB: Frontal Assessment Battery [8].

5 words immediate and delayed: the " 5 words" memory test [9].

Table 1: The neuropsychological evaluation of patient before, 72 hours post lumbar puncture and 6 months after shunt surgery.

However, in the above patients the hydrocephalus was of the obstructive type, or due to ventriculitis or plexitis with an inflammatory exudate. Thus, in such patients so far described in the literature, the hydrocephalus is characterized by increased CSF pressure, and it is not of the normal pressure type, as in our patient. One possible explanation in our case could be the direct effect of inflammatory cells in the CSF, affecting CSF turnover or hydrodynamics. Additionally, no relation between medication and hydrocephalus has been proposed.

The role of CSF shunting for obstructive hydrocephalus in HIV patients is still unclear. In a series of 30 patients with post-tuberculous hydrocephalus, Nadvi et al did not find any improvement by the CSF shunting in the HIV-1 positive group compared with the HIV negative group [13]. One potential contributor to shunt unresponsiveness is the presence of comorbid neurologic conditions that are common in HIV patients. HIV positive patients with tuberculous meningitis may undergo an external CSF drainage and only after significant improvement may be considered for shunt surgery irrespectively of the CD4 count $[13,14]$. Another study showed successful and safe shunting in HIV-1 patients with hydrocephalus secondary to cryptococcal meningitis [15].

To our knowledge, there are no studies on the effect of CSF shunt surgery in HIV-2 patients with NPH. Our HIV-2 patient remains improved in cognitive function and gait 6 months post shunt surgery. The favorable stable course of the present case demonstrates the important role of HAART (from age of 53 to 59) in improvement of many of the imaging findings, besides shunt surgery.

As regards the frontal lesion observed in the 1st imaging of the patient (age 53), it has recently been shown that such lesions may be due to progressive multifocal leucoencephalopathy or secondary infection in most but not all patients [16]. In our patient no paramagnetic enhancement was evident and there was no indication of an opportunistic infection including tuberculosis, cryptococcosis and toxoplasmosis. Furthermore, the lesion practically disappeared following HAART, rendering the possibility of progressive myltifocal leucoencephalopathy rather remote. Thus, this lesion as well as the other smaller white matter lesions should be attributed to the HIV2 infection directly. This unique NPH secondary to HIV-2 case stresses the importance of neuroimaging and laboratory investigations in HIV2 in order to exclude potentially treatable conditions. However, larger samples with prospective design are needed to confirm shunt surgery 
Citation: Paraskevas GP, Bougea A, Kapaki E (2014) Normal Pressure Hydrocephalus in a Human Immunodeficiency Virus Type 2 Patient. J Clin Case Rep 4: 376. doi:10.4172/2165-7920.1000376

as an effective long-term treatment for NPH patients with HIV-2.

\section{References}

1. Kiefer M, Unterberg A (2012) The differential diagnosis and treatment of normal-pressure hydrocephalus. Dtsch Arztebl Int 109: 15-25.

2. Pujari S, Kharkar S, Metellus P, Shuck J, Williams MA, et al. (2008) Normal pressure hydrocephalus: long-term outcome after shunt surgery. J Neurol Neurosurg Psychiatry 79: 1282-1286.

3. Campbell-Yesufu OT, Gandhi RT (2011) Update on human immunodeficiency virus (HIV)-2 infection. Clin Infect Dis 52: 780-787.

4. Matheron S, Pueyo S, Damond F, Simon F, Leprêtre A, et al. (2003) Factors associated with clinical progression in HIV-2 infected-patients: the French ANRS cohort. AIDS 17: 2593-2601.

5. Bienaime A, Colson P, Moreau J, Zandotti C, Pellissier JF, et al. (2006) Progressive multifocal leukoencephalopathy in HIV-2-infected patient. AIDS 20: $1342-1343$

6. Folstein MF, Folstein SE, McHugh PR (1975) "Mini-mental state". A practica method for grading the cognitive state of patients for the clinician. J Psychiat Res 12: 189-198.

7. Royall DR, Cordes JA, Polk M (1998) CLOX: an executive clock drawing task $J$ Neurol Neurosurg Psychiatry 64: 588-594.

8. Dubois B, Slachevsky A, Litvan I, Pillon B (2000) The FAB: a Frontal Assessment Battery at bedside. Neurology 55: 1621-1626.
9. Dubois B, Touchon J, Portet F, Ousset PJ, Vellas B, et al. (2002) "The 5 words": a simple and sensitive test for the diagnosis of Alzheimer's disease]. Presse Med 31: 1696-1699.

10. Eggers C, Vortmeyer A, Emskötter T (1995) Cerebral toxoplasmosis in a patien with the acquired immunodeficiency syndrome presenting as obstructive hydrocephalus. Clin Neuropathol 14: 51-54.

11. Graybill JR, Sobel J, Saag M, van Der Horst C, Powderly W, et al. (2000) Diagnosis and management of increased intracranial pressure in patients with AIDS and cryptococcal meningitis. The NIAID Mycoses Study Group and AIDS Cooperative Treatment Groups. Clin Infect Dis 30:47-54.

12. Basavaprabhu A, Soundarya M, Deepak M, Satish R (2012) CNS toxoplasmosis presenting with obstructive hydrocephalus in patients of retroviral disease--a case series. Med J Malaysia 67: 214-216.

13. Nadvi S S, Nathoo H, Annomalai K, Van Ddellen JR, Bhigjee A (2000) Role of cerebrospinal fluid shunting for human immunodeficiency virus-positive patients with tuberculous meningitis and hydrocephalus: Neurosurgery 473 : 644-650.

14. Palur R, Rajshekhar V, Chandy MJ, Joseph T, Abraham J (1991) Shunt surgery for hydrocephalus in tuberculous meningitis: a long-term follow-up study. J Neurosurg 74: 64-69.

15. Liao CH, Chi CY, Wang YJ, Tseng SW, Chou CH, et al. (2012) Different presentations and outcomes between HIV-infected and HIV-uninfected patients with Cryptococcal meningitis. J Microbiol Immunol Infect 45: 296-304.

16. Haddow LJ, Dudau C, Chandrashekar H, Cartledge JD, Hyare H, et al. (2014) Cross-Sectional Study of Unexplained White Matter Lesions in HIV Positive Individuals Undergoing Brain Magnetic Resonance Imaging. AIDS Patient Care STDS 28: 341-349. 